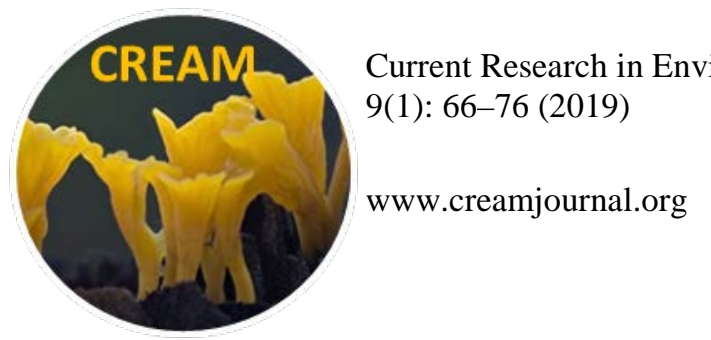

\title{
Nutrient contents and antioxidant properties of Pleurotus spp. cultivated on substrate fortified with Selenium
}

\author{
Fasoranti $\mathrm{OF}^{1}$, Ogidi $\mathrm{CO}^{1,2}$ and Oyetayo $\mathrm{VO}^{1}$
}

${ }^{1}$ Department of Microbiology, The Federal University of Technology, PMB 704, Ondo State, Nigeria

${ }^{2}$ Biotechnology Unit, Department of Biological Sciences, Kings University, PMB 555, Odeomu, Nigeria

Fasoranti OF, Ogidi CO, Oyetayo VO 2019 - Nutrient contents and antioxidant properties of Pleurotus spp. cultivated on substrate fortified with Selenium. Current Research in Environmental \& Applied Mycology (Journal of Fungal Biology) 9(1), 66-76, Doi 10.5943/cream/9/1/7

\begin{abstract}
This study investigated the proximate, mineral, amino acid and antioxidant properties of Pleurotus spp. fortified with selenium. The proximate analysis showed that Pleurotus mushrooms harvested from substrate fortified with selenium are rich in protein with values of $16.35 \%$ and 18.21 for $P$. pulmonarius and $P$. ostreatus, respectively. Low fat content of 0.39 to $0.40 \%$ was obtained in all cultivated mushrooms. Calcium have the highest value of $20.94 \mathrm{mg} / 100 \mathrm{~g}$ in fortified Pleurotus ostreatus. Essential and non- essential amino acids were present in cultivated Pleurotus spp. with the highest values of glutamic acid ranged from 10.61 to $12.27 \mathrm{mg} / 100 \mathrm{~g}$. Ethanolic extract from selenium fortified Pleurotus spp. exhibited higher and better antioxidant effect (91.58 $\%)$ when compared $(\mathrm{p}<0.05)$ to the non-selenium fortified Pleurotus spp. $(75.5 \%)$. Seleniumbiofortification of Pleurotus spp. resulted in a considerable increase of its antioxidant properties. Therefore, selenium enriched Pleurotus species could serve as a rich source of natural antioxidant food for the enhancement of the body against oxidative damage.
\end{abstract}

Key words - Edible mushroom -amino acids - free radicals - mineral-enrichment - nutraceuticals

\section{Introduction}

Mushrooms are able to synthesize a great amount of secondary metabolites that possess antioxidant activities (Ling et al. 2017). The genus Pleurotus, a well-known mushroom belongs to Basidiomycota, order Agaricales, and the family Tricholomataceae (Chang \& Miles 2004). The genus Pleurotus is an important edible mushroom known for its high content of protein as well as low fat content (Krishnamoorthy \& Sankaran 2014). Ling et al. (2017) showed that the mycelia of 10 Pleurotus species with 41 strains of different origin can assimilate selenium (Se) and can therefore present as an excellent dietary source of antioxidant agents. Selenium is classified as a metalloid and, is an essential trace element for animals and humans. Consequently, the importance of dietary selenium in human health has received considerable attention in the last several years (De Silva et al. 2012).

Dietary selenium has been recognized as an antioxidant, and the deficiency of this element has been associated with numerous chronic degenerative diseases, including multiple types of cancer, cardiomyopathy and endemic osteoarthropathy (Fernandes et al. 2015). This element has many physiological functions, but is most often recognized for its role as a cofactor for the enzyme glutathione peroxidase, which is responsible for the removal of free radicals that reduce oxidative 
damage in cells (Facchini et al. 2014). In several regions of the world, the content of selenium in the general diet has been estimated to be insufficient to maintain the proper level of activity of protective seleno-enzymes (Mishra et al. 2013). The specific type of selenium that is ingested is an important factor for the determination of toxicity, nutritional importance and metabolic factors (Facchini et al. 2014).

Oxidative stress is a well-known phenomenon caused by an imbalance between formation and removal of reactive micro-molecules such as reactive oxygen species (ROS) (Bhatia et al. 2014). The term ROS may refer to both the oxygen centered radicals and non-radical derivatives of $\mathrm{O}_{2}$ such as hydrogen peroxide, singlet oxygen, and hypochlorous acid (Huang et al. 2015). These reactive molecules may be produced in all mammalian cells in response to exogenous stimuli through normal cellular metabolism or activation of membrane-bound enzymes (Li \& Shah 2015). Oxidative stress has the potential to damage cells and may eventually lead to cancer, cardiovascular diseases, diabetes, aging, and a vast number of other illnesses and disorders (Mishra et al. 2013). The human body's defense system responds to oxidative stress generally through scavenging or lessening ROS formation using endogenous and/or diet-derived molecules (Mitra et al. 2013). However, the antioxidant defense system needs to be assisted by consumption of antioxidantcontaining supplements. The increasing carcinogenic risks associated with consuming synthetic antioxidants, has caused interest to replace synthetic antioxidants by natural sources of antioxidants, namely vegetables, herbs, fruits and mushrooms (Ren et al. 2015, Sharareh et al. 2016).

Pleurotus mushrooms are rich in vitamin and selenium content which are the important natural antioxidants in biological systems (Vamanu 2012). Free radical scavenging and Nitric Oxide Synthase (NOS) activation properties of water soluble crude polysaccharide from $P$. ostreatus showed superior antioxidant property, which might be due to presence of $\beta$-glucan (Saha et al. 2012). Oyster mushrooms are now widely used as ingredient in dietary supplements to maintain health and prevent diseases, due to their higher free radical scavenging activities (Yang et al. 2002). Keeping in view the health benefits of mushrooms and selenium, this study was conducted to determine the effects of selenium-fortification on the proximate, mineral, amino acid contents and antioxidant activities of $P$. ostreatus and $P$. pulmonarius.

\section{Materials \& Methods}

\section{Collection of corn cobs}

The corn cobs used as substrates for this research work were procured at the King's market, Akure, Ondo State.

\section{Source of Pleurotus spp. Spawn}

Spawns of Pleurotus ostreatus and Pleurotus pulmonarius were obtained from Federal Institute of Industrial Research (FIIRO), Oshodi Lagos, Nigeria.

\section{Substrate Preparation}

The substrates (corn cobs) were sundried and broken into smaller pieces using mortar and pestle. It was further pulverized into fine powdered using a mill machine (5657 HAAN 1 TYPE ZM1, Retsch GmbH, Haan, Germany). The substrate (corn cobs) was moistened with water to a concentration of $60 \%$. One thousand grams $(1000 \mathrm{~g})$ of the substrate was packed into polypropylene bags and sealed with paper with the aid of polyvinyl rings. The bags were then autoclaved for 2 hours at $121{ }^{\circ} \mathrm{C}$

\section{Mushroom Preparation}

The substrates were allowed to cool down and then inoculated with $30 \mathrm{~g}$ of Pleurotus spawn. Sodium selenite (50 mg/Kg) was injected into each substrate. A control treatment with no sodium selenite was also prepared. The bags were then kept in spawn room with $75 \%$ relative humidity 
until formation of primordial. The bags were then uncapped and transferred to the fruiting room to allow the normal development of the fruitbodies.

\section{Proximate and mineral analysis of cultivated Pleurotus spp.}

The proximate analysis of the cultivated Pleurotus spp. were carried out according to the method of AOAC (2005). The harvested mushrooms were dried at $26{ }^{\circ} \mathrm{C}$ for 6 days before proximate analysis was carried out. The minerals of the mushroom were analyzed using the samples obtained by ashing at $550{ }^{\circ} \mathrm{C}$ and dissolving in $\mathrm{HCl}(25 \mathrm{~mL})$ and $5 \%$ lanthanum chloride ( $2 \mathrm{~mL}$ ), boiled, filtered and make it up to standard volume with deionized water (AOAC 2005). Mn, $\mathrm{Cu}, \mathrm{Co}, \mathrm{Zn}, \mathrm{Fe}, \mathrm{Mg}$, and Ca were determined with a Buck Atomic Absorption Spectrometer (Buck Scientific, Model 200A/200, Inc. East Norwalk, Connecticut, U.S.A).

\section{Determination of amino acid content of cultivated Pleurotus spp.}

The amino acid profile of Pleurotus spp. was determined using the method described by Benitez (1989). Four stages were involved in the determination of the amino acid content of Pleurotus spp. Five grams ( $5 \mathrm{~g}$ ) of the samples were dried to constant weight, defatted, hydrolysed, evaporated in a rotary evaporator and loaded into Applied Biosystems PTH Amino Acid Analyzer.

\section{Preparation of mushroom extracts from cultivated mushrooms}

The mushroom samples were cut into small pieces and air-dried. The dried sample was ground into fine powder. Mushroom sample (250 g) was soaked in $1000 \mathrm{ml}$ of ethanol and kept for three days with occasional shaking. Each portion was then filtered using Whatman filter paper No 1. The filtrates were concentrated and the extracts (residues) were stored at $4{ }^{\circ} \mathrm{C}$ in a sterile container for future use.

\section{DPPH free radical scavenging activity of extracts from harvested Pleurotus spp.}

The scavenging ability of extracts of the cultivated Pleurotus spp. on 1, 1-diphenyl-2picrylhydrazyl (DPPH) radicals was determined according to the method of Tibuhwa et al. (2012). Each extract (0.01-0.14 mg/ml) was mixed with $1 \mathrm{ml}$ of ethanolic extract containing DPPH radicals $(0.4 \mathrm{mM})$ (A1). The mixture was shaken vigorously and left to stand for $30 \mathrm{~min}$ in the dark. The absorbance was measured at $515 \mathrm{~nm}$. Absorbance of the controls solution containing only DPPH (A0) and the sample extract solution without DPPH (As) was also measured at $515 \mathrm{~nm}$. The percentage of DPPH radical scavenging activity of each extract was determined within the range of dose response and was calculated as:

$$
\mathrm{DPPH} \text { radical scavenging activity }(\%)=\frac{\mathrm{A} 0-(\mathrm{A} 1-\mathrm{As})}{\mathrm{A} 0} \times 100
$$

Where

$\mathrm{A} 0=$ Absorbance of the control solution containing only DPPH

A1 = Absorbance in the presence of mushroom extract in DPPH solution

As $=$ The absorbance of the sample extract solution without DPPH

\section{Hydroxyl radical scavenging ability of extracts from harvested Pleurotus spp.}

The determination of scavenging effect on hydroxyl radical was carried out as described in Oyetayo et al. (2009). The reaction mixture in a final volume of $1.0 \mathrm{ml}$, containing $0.4 \mathrm{ml}$ of 20 $\mathrm{mmol} / \mathrm{ml}$ sodium phosphate buffer ( $\mathrm{pH} 7.4$ ), $0.1 \mathrm{ml}$ of $0.125-2 \mathrm{mg} / \mathrm{ml}$ extracts, $0.1 \mathrm{ml}$ of $60 \mathrm{nmol} / \mathrm{L}$ deoxyribose, $0.1 \mathrm{ml}$ of $10 \mathrm{mmol} / \mathrm{L}$ hydrogen peroxide, $0.1 \mathrm{ml}$ of $1 \mathrm{mmol} / \mathrm{L}$ ferric chloride, $0.1 \mathrm{ml}$ of $1.04 \mathrm{mmol} / \mathrm{L}$ EDTA and $0.1 \mathrm{ml}$ of $2 \mathrm{mmol} / \mathrm{L}$ ascorbic acid was incubated at $37{ }^{\circ} \mathrm{C}$ for 1 hour. Solutions of $\mathrm{FeCl}_{2}$ and ascorbic acid were made up immediately before use in de-ionised water. The reaction was stopped by adding $1 \mathrm{ml}$ of $17 \mathrm{mmol} / \mathrm{L}$ thiobarbituric acid (TBA) and $1 \mathrm{ml}$ of 17 
$\mathrm{mmol} / \mathrm{L}$ trichloroacetic acid (TCA). The mixture was boiled for $15 \mathrm{~min}$, cooled in ice and then the absorbance measured at $532 \mathrm{~nm}$ using a UNICO 2100 spectrophotometer (As). BHT was used as positive control while distilled water in place of extracts or BHT was used as blank (Ab) and the samplesolution without adding deoxyribose as sample blank (Asb).

$$
\text { Scavenging activity }(\%)=\frac{\mathrm{Ab}-(\mathrm{As}-\mathrm{Asb})}{\mathrm{Ab}} \times 100
$$

Where Ab, As and Asb are the absorbance at $532 \mathrm{~nm}$ of the blank, the extract or BHT and the sample blank without deoxyribose, respectively.

\section{Ferric Reducing Antioxidant Power (FRAP) of extracts from harvested Pleurotus spp.}

Ferric reducing antioxidant power (FRAP) assay was done according to the method of Dong et al. (2014). The oxidant in the FRAP assay was prepared by mixing 2,4,6-tri(2-pyridyl)-s-triazine (10 mM in $40 \mathrm{mMHCl}, 2.5 \mathrm{ml})$, acetate buffer $(0.3 \mathrm{M} \mathrm{pH} 3.6,25 \mathrm{ml})$, and $2.5 \mathrm{ml}$ of $\mathrm{FeCl}_{36} \mathrm{H}_{2} \mathrm{O}(20$ $\mathrm{mM}$ ). The combination prepared by mixing all these reagents is known as FRAP reagent. An amount of $1.8 \mathrm{ml}$ of freshly prepared FRAP reagent, $100 \mathrm{ml}$ of ethanolic extract and $100 \mathrm{ml}$ of distilled water was added to the test tube. The tubes were then incubated at $37^{\circ} \mathrm{C}$ for 30 minutes and absorbance was taken at $595 \mathrm{~nm}$ in spectrophotometer (Perkin Elmer UV/VIS).

\section{Statistical analysis}

Data obtained were analyzed using analysis of variance (ANOVA). Means were separated using Duncan's New Multiple Range Test at 95\% confidence level using Statistical Packages for the Social Sciences (SPSS) version 17.0. Differences between means were considered significant at $\mathrm{P} \leq 0.05$.

\section{Results}

The proximate composition of the cultivated Pleurotus spp. in percentage is presented in Table 1. Higher protein contents of $16.35 \%$ and $18.21 \%$ were found in Pleurotus pulmonarius and Pleurotus ostreatus fortified with selenium. The carbohydrate content in cultivated Pleurotus spp. (non-fortified and fortified with selenium) are not significantly different $(\mathrm{p}<0.05)$ form each other with their values ranging from 53.84 to $58.10 \%$. Low fat content of 0,39 to $0.40 \%$ was obtained in cultivated mushrooms. Table 2 shows the mineral composition (mg/100 g) of cultivated Pleurotus species. The results revealed that calcium (1.78 to $20.94 \mathrm{mg} / 100 \mathrm{~g}$ ) was the highest occurring mineral in all mushroom samples, while nickel $(0.01$ to $0.03 \mathrm{mg} / 100 \mathrm{~g})$ was the least occurring mineral and no lead content observed. The amino acid composition (mg/100 g) of the cultivated Pleurotus species were recorded in Table 3. Glutamic acid had the highest values ranging from 10.61 to 12.27. The presence of essential and non-essential amino acids was obtained in both fortified and non- fortified Pleurotus species. Fig. 1 shows the DPPH scavenging effects of extracts of the cultivated Pleurotus spp. Extracts from selenium fortified Pleurotus ostreatus (POS) exhibited the greatest DPPH scavenging effects (45.09-97.92\%) at concentrations of $50 \mu \mathrm{g} / \mathrm{ml}$ and $250 \mu \mathrm{g} / \mathrm{ml}$, respectively, while extracts of non- selenium fortified Pleurotus ostreatus (PON) had the least scavenging effects on DPPH radicals (27.81-74.45\%) at concentrations of $50 \mu \mathrm{g} / \mathrm{ml}$ and $250 \mu \mathrm{g} / \mathrm{ml}$ respectively. Fig. 2 shows the hydroxyl ion scavenging effects of the cultivated Pleurotus spp. Selenium fortified Pleurotus spp. (POS and PPS) exhibited moderate and concentration dependent hydroxyl radical scavenging ability than non- selenium fortified Pleurotus spp. selenium fortified Pleurotus ostreatus (POS) and fortified Pleurotus pulmonarius (PPS) had hydroxyl ion scavenging ability of $91.58 \%$ at $250 \mu \mathrm{g} / \mathrm{ml}$ and $88.45 \%$ at $250 \mu \mathrm{g} / \mathrm{ml}$, respectively. Non- selenium fortified Pleurotus ostreatus (PON) and non- selenium fortified Pleurotus pulmonarius (PPN) at a concentration of $250 \mu \mathrm{g} / \mathrm{ml}$ had hydroxyl ion scavenging effects of 75.50 selenium and $69.89 \%$ respectively. Fig. 3 shows that ferric reductive capacity of the extracts is 
concentration dependent. Selenium enriched Pleurotus species exhibited a better $(p \leq 0.05)$ reducing power than non-enriched Pleurotus species. The POS, PPS, PON and PPN exhibited highest reducing power at $1.68,1.62,1.52$ and 1.48 respectively at $250 \mu \mathrm{g} / \mathrm{ml}$ concentration.

\section{Discussion}

The protein contents of Pleurotus spp. were found to be higher in selenium enriched Pleurotus spp. Turlo et al. (2010) reported $213.9 \mathrm{mg} / 100 \mathrm{~g}$ from selenium enriched Lentinus edodes. Similarly, Akyuz et al. (2010) reported relatively higher protein content of 17 to $42 \mathrm{~g}$ per $100 \mathrm{~g}$ dried fruitbodies of $P$. ostreatus. The researchers also stated that the content of protein in $P$. ostreatus vary according to strains, substrate-mineral enrichment, physical and chemical differences in growth medium, composition of the substrate, size of the pileus, and harvest time. Carbohydrate content in Pleurotus spp. constitutes the major component of mushroom dry matter, usually about 50-60\% (Kalac 2012). Synytsya et al. (2010) reported the composition of these polysaccharides in mushroom fruit bodies vary with the strains, ranging from 37 to $48 \mathrm{~g} / 100 \mathrm{~g}$ dry fruit bodies, which were lower than the result of this study.

Table 1 Proximate composition (\%) of cultivated Pleurotus spp.

\begin{tabular}{lllll}
\hline Parameters & PPN & PPS & POS & PON \\
\hline Moisture & $9.03 \pm 0.03^{\mathrm{b}}$ & $8.56 \pm 0.01^{\mathrm{a}}$ & $9.77 \pm 0.00^{\mathrm{b}}$ & $9.02 \pm 0.00^{\mathrm{b}}$ \\
Ash & $6.20 \pm 0.03^{\mathrm{b}}$ & $8.21 \pm 0.59^{\mathrm{bc}}$ & $5.12 \pm 0.00^{\mathrm{a}}$ & $5.93 \pm 0.03^{\mathrm{a}}$ \\
Protein & $10.31 \pm 0.00^{\mathrm{a}}$ & $16.35 \pm 0.01^{\mathrm{b}}$ & $18.21 \pm 0.00^{\mathrm{c}}$ & $10.69 \pm 0.00^{\mathrm{a}}$ \\
Crude fibre & $19.70 \pm 0.00^{\mathrm{c}}$ & $11.82 \pm 0.06^{\mathrm{b}}$ & $10.40 \pm 0.02^{\mathrm{a}}$ & $20.12 \pm 0.02^{\mathrm{c}}$ \\
Fat & $0.40 \pm 0.00^{\mathrm{a}}$ & $0.39 \pm 0.01^{\mathrm{a}}$ & $0.40 \pm 0.00^{\mathrm{a}}$ & $0.40 \pm 0.00^{\mathrm{a}}$ \\
Carbohydrates & $54.36 \pm 0.01^{\mathrm{a}}$ & $54.67 \pm 0.00^{\mathrm{a}}$ & $58.10 \pm 0.00^{\mathrm{a}}$ & $53.84 \pm 0.00^{\mathrm{a}}$ \\
\hline
\end{tabular}

Values carrying the same alphabets in the same row are not significantly different at $(\mathrm{p}<0.05)$. Values are means of triplicates \pm SD.

Keys: PPN - Pleurotus pulmonarius (non-fortified with selenium)

PPS - Pleurotus pulmonarius (fortified with selenium)

PON - Pleurotus ostreatus (non-fortified with selenium)

POS - Pleurotus ostreatus (fortified with selenium)

Table 2 Mineral composition* (mg/100-g) of cultivated Pleurotus spp.

\begin{tabular}{lllll}
\hline Mineral & PPN & PPS & POS & PON \\
\hline Zinc & $0.07 \pm 0.01^{\mathrm{a}}$ & $0.25 \pm 0.03^{\mathrm{b}}$ & $0.29 \pm 0.00^{\mathrm{c}}$ & $0.42 \pm 0.00^{\mathrm{d}}$ \\
Iron & $0.03 \pm 0.00^{\mathrm{a}}$ & $1.97 \pm 0.03^{\mathrm{c}}$ & $0.73 \pm 0.02^{\mathrm{b}}$ & $2.15 \pm 0.04^{\mathrm{d}}$ \\
Copper & $0.09 \pm 0.07^{\mathrm{a}}$ & $0.13 \pm 0.00^{\mathrm{a}}$ & $0.13 \pm 0.10^{\mathrm{a}}$ & $0.21 \pm 0.01^{\mathrm{a}}$ \\
Calcium & $5.66 \pm 0.46^{\mathrm{b}}$ & $10.62 \pm 0.56^{\mathrm{c}}$ & $20.94 \pm 0.16^{\mathrm{d}}$ & $1.78 \pm 0.02^{\mathrm{a}}$ \\
Magnesium & $3.07 \pm 0.05^{\mathrm{a}}$ & $4.34 \pm 0.17^{\mathrm{c}}$ & $3.84 \pm 0.11^{\mathrm{b}}$ & $2.56 \pm 0.89^{\mathrm{a}}$ \\
Nickel & $0.00 \pm 0.00^{\mathrm{a}}$ & $0.03 \pm 0.01^{\mathrm{c}}$ & $0.01 \pm 0.01^{\mathrm{b}}$ & $0.00 \pm 0.00^{\mathrm{a}}$ \\
Chromium & $0.01 \pm 0.01^{\mathrm{a}}$ & $0.02 \pm 0.00^{\mathrm{b}}$ & $0.05 \pm 0.01^{\mathrm{c}}$ & $0.07 \pm 0.00^{\mathrm{d}}$ \\
Cadmium & $0.04 \pm 0.00^{\mathrm{a}}$ & $0.01 \pm 0.00^{\mathrm{a}}$ & $0.03 \pm 0.02^{\mathrm{b}}$ & $0.01 \pm 0.00^{\mathrm{a}}$ \\
Manganese & $0.01 \pm 0.00^{\mathrm{a}}$ & $0.17 \pm 0.00^{\mathrm{b}}$ & $0.18 \pm 0.00^{\mathrm{c}}$ & $0.31 \pm 0.00^{\mathrm{d}}$ \\
Lead & $0.00 \pm 0.00^{\mathrm{a}}$ & $0.00 \pm 0.00^{\mathrm{a}}$ & $0.00 \pm 0.00^{\mathrm{a}}$ & $0.00 \pm 0.00^{\mathrm{a}}$ \\
\hline
\end{tabular}

Values carrying the same alphabets in the same row are not significantly different at $(\mathrm{p}<0.05)$. Values are means of triplicates \pm SD.

*selenium concentration of the cultivated Pleurotus spp. has been reported in our previous study (Fasoranti et al. 2018)

Keys: PPN - Pleurotus pulmonarius (non-fortified with selenium)

PPS - Pleurotus pulmonarius (fortified with selenium)

PON - Pleurotus ostreatus (non-fortified with selenium)

POS - Pleurotus ostreatus (fortified with selenium) 
Table 3 Amino acid composition (mg/100g) of cultivated Pleurotus spp.

\begin{tabular}{lllll}
\hline Amino acid & PPS & POS & PON & PPN \\
\hline Cysteine & $0.67 \pm 0.13^{\mathrm{a}}$ & $1.16 \pm 0.13^{\mathrm{c}}$ & $1.22 \pm 0.12^{\mathrm{c}}$ & $0.93 \pm 0.12^{\mathrm{b}}$ \\
Alanine & $3.09 \pm 0.12^{\mathrm{a}}$ & $3.43 \pm 0.13^{\mathrm{b}}$ & $4.15 \pm 0.13^{\mathrm{c}}$ & $3.16 \pm 0.13^{\mathrm{a}}$ \\
Glutamic acid & $10.61 \pm 0.13^{\mathrm{a}}$ & $11.79 \pm 0.13^{\mathrm{b}}$ & $12.27 \pm 0.14^{\mathrm{c}}$ & $11.18 \pm 0.13^{\mathrm{b}}$ \\
Glycine & $3.69 \pm 0.13^{\mathrm{a}}$ & $4.14 \pm 0.13^{\mathrm{b}}$ & $4.56 \pm 0.13^{\mathrm{c}}$ & $3.83 \pm 0.12^{\mathrm{a}}$ \\
Serine & $1.67 \pm 0.13^{\mathrm{a}}$ & $2.67 \pm 0.13^{\mathrm{c}}$ & $3.33 \pm 0.13^{\mathrm{d}}$ & $2.34 \pm 0.13^{\mathrm{b}}$ \\
Aspartic acid & $4.53 \pm 0.13^{\mathrm{a}}$ & $5.43 \pm 0.13^{\mathrm{c}}$ & $7.76 \pm 0.13^{\mathrm{d}}$ & $5.15 \pm 0.13^{\mathrm{b}}$ \\
Proline & $2.36 \pm 0.14^{\mathrm{a}}$ & $3.38 \pm 0.13^{\mathrm{b}}$ & $3.77 \pm 0.12^{\mathrm{c}}$ & $3.17 \pm 0.13^{\mathrm{b}}$ \\
Arginine & $4.63 \pm 0.13^{\mathrm{a}}$ & $5.13 \pm 0.13^{\mathrm{b}}$ & $5.63 \pm 0.13^{\mathrm{c}}$ & $4.95 \pm 0.14^{\mathrm{b}}$ \\
Tyrosine & $2.54 \pm 0.12^{\mathrm{a}}$ & $3.22 \pm 0.13^{\mathrm{b}}$ & $3.57 \pm 0.12^{\mathrm{c}}$ & $2.73 \pm 0.12^{\mathrm{a}}$ \\
Isoleucine & $2.43 \pm 0.13^{\mathrm{a}}$ & $3.66 \pm 0.13^{\mathrm{c}}$ & $4.44 \pm 0.13^{\mathrm{d}}$ & $3.30 \pm 0.14^{\mathrm{b}}$ \\
Histidine & $1.28 \pm 0.13^{\mathrm{a}}$ & $1.63 \pm 0.13^{\mathrm{b}}$ & $2.17 \pm 0.13^{\mathrm{c}}$ & $1.34 \pm 0.13^{\mathrm{a}}$ \\
Leucine & $3.13 \pm 0.13^{\mathrm{a}}$ & $3.43 \pm 0.13^{\mathrm{b}}$ & $5.68 \pm 0.08^{\mathrm{c}}$ & $3.53 \pm 0.13^{\mathrm{b}}$ \\
Lysine & $2.67 \pm 0.13^{\mathrm{a}}$ & $3.58 \pm 0.13^{\mathrm{c}}$ & $4.26 \pm 0.13^{\mathrm{d}}$ & $3.15 \pm 0.13^{\mathrm{b}}$ \\
Tryptophan & $1.31 \pm 0.13^{\mathrm{a}}$ & $1.23 \pm 0.13^{\mathrm{a}}$ & $1.39 \pm 0.13^{\mathrm{a}}$ & $1.33 \pm 0.13^{\mathrm{a}}$ \\
Valine & $2.91 \pm 0.13^{\mathrm{a}}$ & $3.64 \pm 0.13^{\mathrm{b}}$ & $4.13 \pm 0.13^{\mathrm{c}}$ & $3.34 \pm 0.13^{\mathrm{b}}$ \\
Methione & $0.69 \pm 0.13^{\mathrm{a}}$ & $1.04 \pm 0.13^{\mathrm{b}}$ & $1.46 \pm 0.13^{\mathrm{c}}$ & $0.85 \pm 0.13^{\mathrm{a}}$ \\
Phenylalanine & $3.31 \pm 0.13^{\mathrm{a}}$ & $3.49 \pm 0.13^{\mathrm{b}}$ & $4.13 \pm 0.13^{\mathrm{c}}$ & $3.68 \pm 0.13^{\mathrm{b}}$ \\
Threonine & $2.63 \pm 0.12^{\mathrm{a}}$ & $2.46 \pm 0.16^{\mathrm{a}}$ & $3.51 \pm 0.12^{\mathrm{b}}$ & $2.85 \pm 0.13^{\mathrm{a}}$ \\
\hline Values carrying & Same & $\mathrm{al} h \mathrm{~b}$ &
\end{tabular}

Values carrying the same alphabets in the same row are not significantly different at ( $>>0.05)$.

Values are means of triplicates \pm SD.

Key: $\quad$ PPN - Pleurotuspulmonarius (non-fortified with selenium)

PPS - Pleurotuspulmonarius (fortified with selenium)

PON - Pleurotusostreatus (non-fortified with selenium)

POS - Pleurotusostreatus (fortified with selenium)

The minerals found to be present in the cultivated Pleurotus spp. include zinc, iron, copper, calcium, magnesium, nickel, chromium, cadmium, and manganese. These minerals are chemical elements that are fundamental for the normal metabolic functioning of the body (Wenk \& Bulakh 2004). The minerals play essential structural and metabolic roles. Calcium, magnesium and iron which are nutritionally important were found in reasonable amount, while manganese and copper were in lower amount. The preponderance of calcium in these mushrooms may be due to the absorption and accumulation of this element from their substrate. Minerals generally in the diet are required for metabolic reactions, transmission of nerve impulses, rigid bone formation and regulation of water and salt balance among others (Skinner 2005).

Glutamic acid was the most abundant non-essential amino acid in the cultivated mushrooms. Amino acid profiling revealed that the levels of amino acids in our study were higher as compared to some of the commonly consumed species, Agaricus bisporus and Pleurotus sajor-caju in the findings of Kayode et al. (2015). A similar kind of increment due to the selenium enrichment has also been reported by Hua et al. (2000). It has been reported that the inorganic selenium compounds get bio-transformed into the seleno-compounds (Vetchinkina et al. 2013). These compounds, in turn, get reduced to hydrogen selenides, which are the key intermediates for facilitating the biosynthesis of selenocysteine and other non-amino acid selenoproteins (Falandysz 2008). This notable difference in the amino acid profile in Pleurotus spp. fruitbodies obtained could due to the activation of biosynthesis of the polysaccharides by the selenium bioaccumulation.

Pleurotus mushrooms are rich in biologically active compounds, which are the important natural antioxidants in biological systems (Chang \& Miles 1989). In this study, the total antioxidant content of the ethanol extracts of Se-enriched mushrooms was significantly higher than the nonenriched Pleurotus species. Jayakumar et al. (2011) reported that an extract of P. ostreatus exhibit in vitro antioxidant activity by virtue of its scavenging hydroxyl and superoxide radicals, inhibiting lipid peroxidation, reducing power on ferric ions, chelating ferrous ions and quenching 2,3diazabicyclo[2,2,2] oct-2-ene (DBO). Similarly, Zhang et al. (2012) revealed that the fruiting bodies 
of $P$. ostreatus exhibited stronger DPPH and superoxide anion radical scavenging activity with increased concentration. Free radical scavenging and Nitric Oxide Synthase (NOS) activation properties of water soluble crude polysaccharide from $P$. ostreatus showed superior antioxidant property, which might be due to presence of carbohydrate component; mostly $\beta$-glucan that seems to be responsible for the antioxidant activity (Mitra et al. 2013).

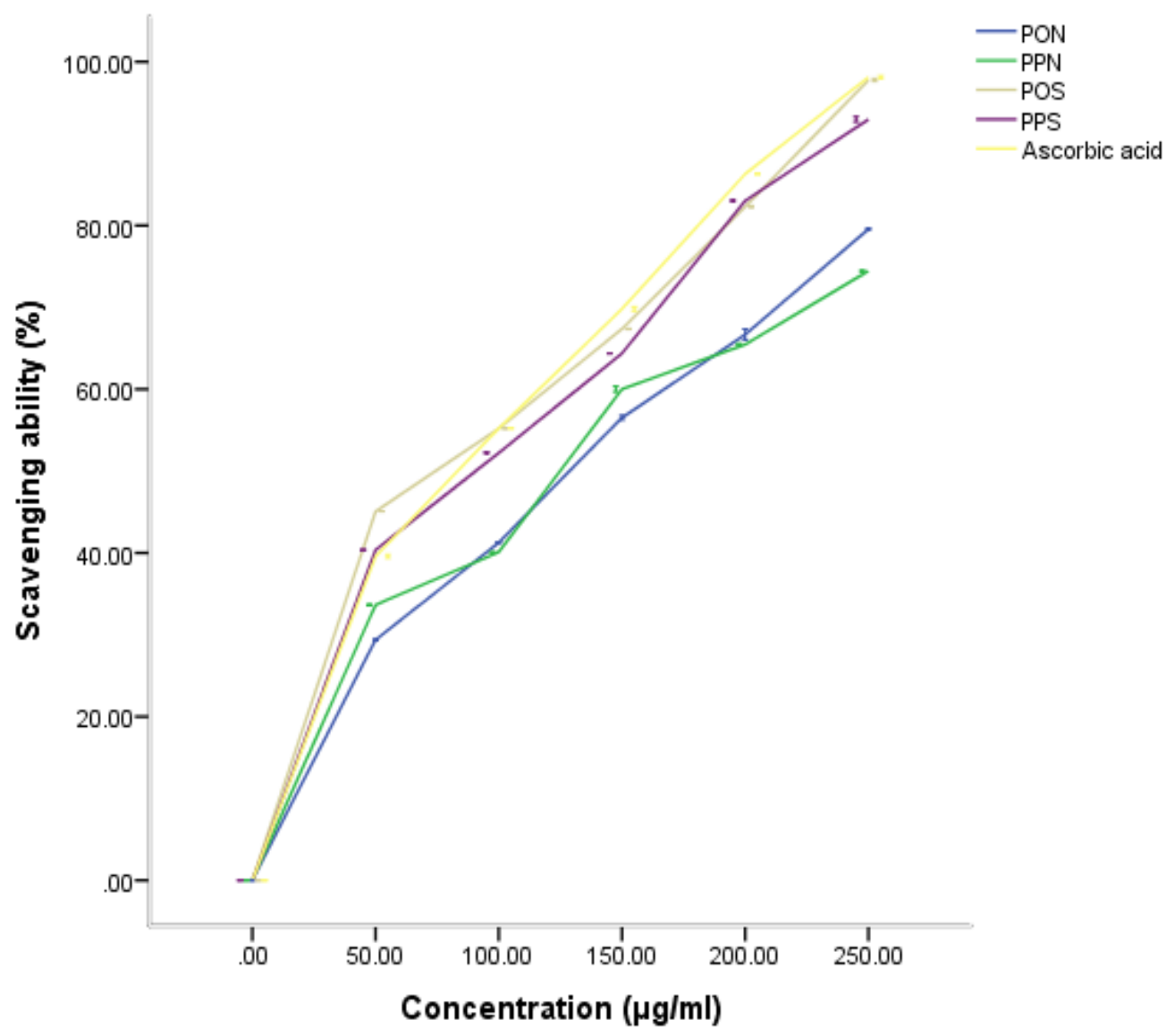

Fig. 1 - DPPH Scavenging ability of cultivated Pleurotus spp.

Keys: PPN - Pleurotus pulmonarius (non-fortified with selenium)

PPS - Pleurotus pulmonarius (fortified with selenium)

PON - Pleurotus ostreatus (non-fortified with selenium)

POS - Pleurotus ostreatus (fortified with selenium)

The results in the present study revealed that ethanolic extracts of Se-enriched Pleurotus ostreatus act as free radical scavengers, indicating the potential use of Se-enrich mushrooms as antioxidants in diet. Selenium enriched Pleurotus spp. exhibited moderate and concentration dependent hydroxyl radical scavenging ability than non-enriched Pleurotus ostreatus. The inhibitory ability of Se-Pleurotus species on hydroxyl radical was directly related to their concentrations. At the concentration of $250 \mathrm{ug} / \mathrm{ml}$, the hydroxyl scavenging activity was $91.58 \%$ for POS and $88.48 \%$ for PPS respectively. The result of this study is similar to Wei et al. (2015) who reported that mushrooms enriched with selenium displayed stronger scavenging activity of superoxide radical. Similarly, it was reported that Selenium exopolysaccharide from Lactococcus lactis and Se-enriched Maitake polysaccharide displayed higher antioxidant activities than the nonselenium fortified polysaccharide (Guo et al. 2013, Mao et al. 2014). The mechanism of scavenging free radicals may be the presence of three-dimensional structure of polysaccharide that has been changed by the selenyl group (SeH) or seleno-acid ester and increasing hydroxyl groups, which affected the hydrogen atom-donating capacity and antioxidant ability (Wang et al. 2016). Otherwise, selenium itself has stronger antioxidant activity. 


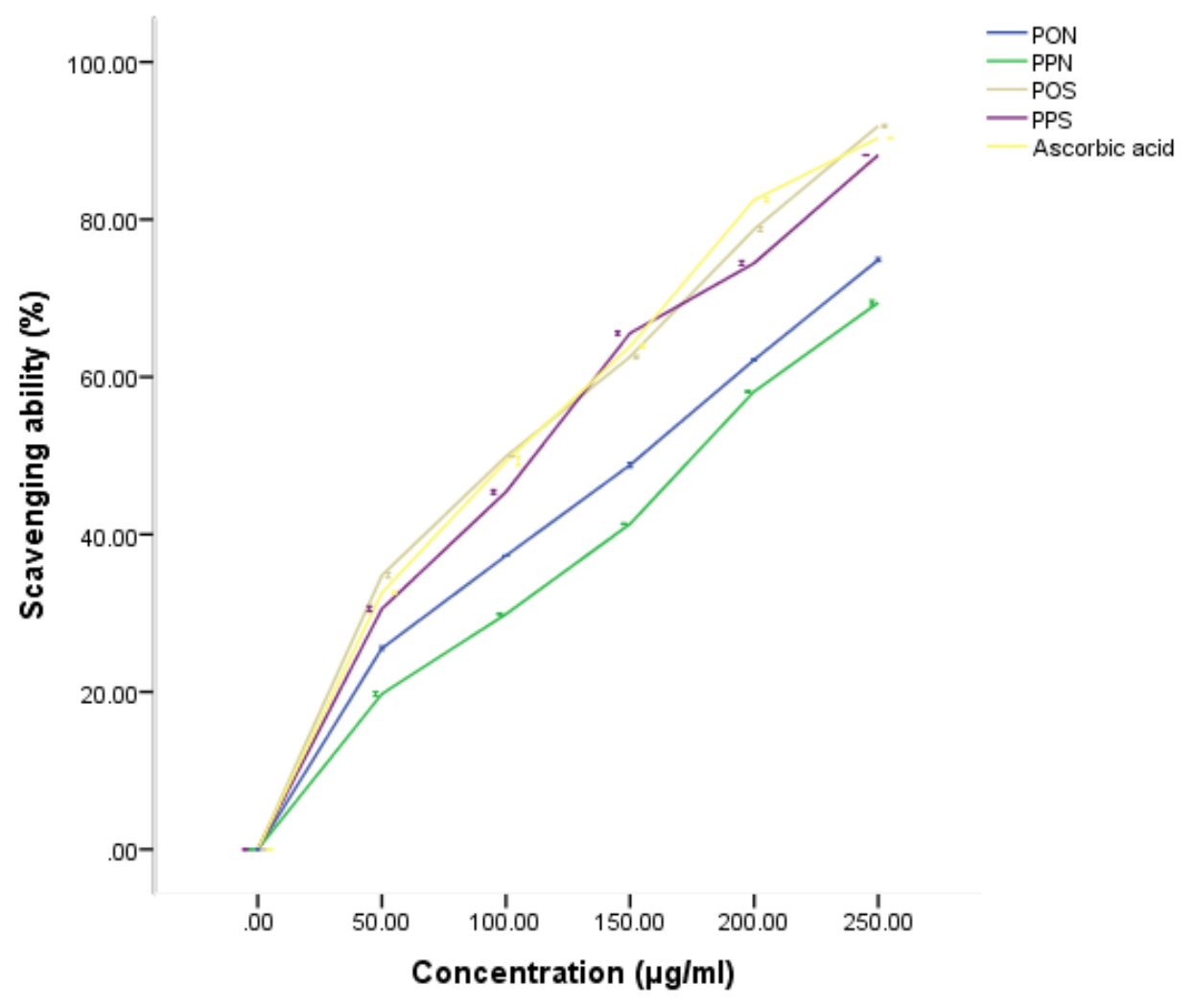

Fig. 2 - Hydroxyl radical scavenging ability of cultivated Pleurotus spp.

Keys: PPN - Pleurotus pulmonarius (non-fortified with selenium)

PPS - Pleurotus pulmonarius (fortified with selenium)

PON - Pleurotus ostreatus (non-fortified with selenium)

POS - Pleurotus ostreatus (fortified with selenium)

The reductive capacity of the extracts is concentration dependent. Selenium enriched Pleurotus spp. exhibited a better and significantly reducing power than non-enriched Pleurotus spp. Mushrooms are known to possess antioxidant and reducing ability due to the presence of phenols and terpenoids. A number of studies suggested that the addition of selenium triggers the synthesis of selenoergothenoine by replacing sulphur with the selenium compound from the antioxidative ergotheionine moiety (Beelman \& Royse 2006). The current finding is corroborated by the study of Bhatia et al. (2014), where extracts of the Se-enriched P. sajor-caju and Volvariella volacea mushroom spp. exhibited higher reducing and scavenging activitie. A recent study conducted by Poniedzialek et al. (2017) reported that biofortification of P. ostreatus and P. eryngii with selenium significantly improved their antioxidant and reducing activities, indicating the potential applicability of such bio-fortified ingredients as functional food.

Generally, fruitbodies of Pleurotus possessed higher concentration of antioxidants than other commercial mushrooms (Sharareh et al. 2016). This activity was mainly due to presence of polysaccharide pleuran ( $\beta$-glucan) that has been isolated from $P$. ostreatus showing a positive effect on rat colon with pre-cancerous lesions (Sharareh et al. 2016). Oyster mushrooms are now widely used as ingredients in dietary supplements to maintain health and prevent diseases due to their higher free radical scavenging activities (Yang et al. 2002).

Conclusively, the Selenium-enriched Pleurotus spp. showed significant antioxidant property. Therefore, selenium enriched Pleurotus spp. could serve as a rich source of natural antioxidant food for the enhancement of the body against oxidative damage. Fortification of Pleurotus spp. with essential metals should be encouraged as this can improve its application as health promoting foods. 


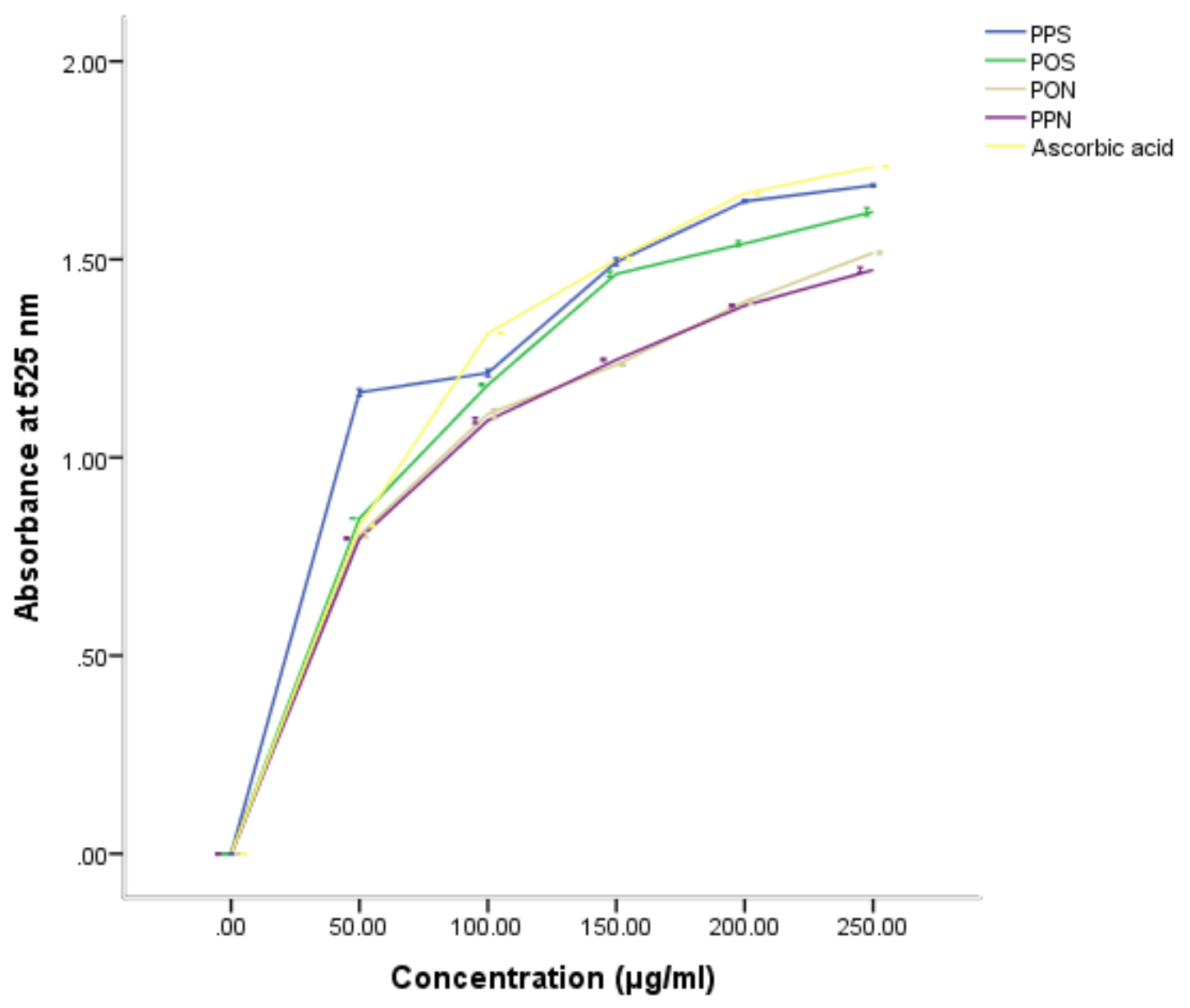

Fig. 3 - Reducing power of cultivated Pleurotus spp.

Keys: PPN - Pleurotus pulmonarius (non-fortified with selenium)

PPS - Pleurotus pulmonarius (fortified with selenium)

PON - Pleurotus ostreatus (non-fortified with selenium)

POS - Pleurotus ostreatus (fortified with selenium)

\section{References}

Akyuz M, Onganer AN, Erecevit P, Kirbag S. 2010 - Antimicrobial activity of some edible mushrooms in the eastern and southeast Anatolia region of Turkey. Gazi University Journal of Science, 23(2), 125-130.

AOAC. 2005 - (Association of Official Analytical Chemists) Official Methods of Analysis of the Association of Analytical Chemists International, $18^{\text {th }}$ ed. Gathersburg, MD USA

Beelman RB, Royse DJ 2006 - Selenium enrichment of Pleurotus cornucopiae (Paulet) Rouant and Grifola frondosa (Dicks: Fr.) S.F. gray mushrooms. International Journal of Medicinal Mushroom, 8, 1-8

Benitez LV. 1989 - Amino acid and fatty acid profiles in aquaculture nutrition studies. In S.S. De Silva (Ed.) Fish Nutrition Research in Asia: Proceedings of the Third Asian Fish Nutrition Network Meeting. Manila, Philippines: Asian Fisheries Society. Pp 23-25

Bhatia P, Bansala C, Prakashb R, Nagarajac T. 2014 - Selenium uptake and associated anti-oxidant properties in Pleurotus fossulatus cultivated on wheat straw from seleniferous fields. Acta Alimentaria, 43(2), 280-287.

Chang S, Miles PG. 2004 - Pleurotus: A mushroom of road adaptability: cultivation, nutritional value, medicinal effect, and environmental impact. $2^{\text {nd }}$ Edition, CRC Press, Boca Raton, 315325. 
Chang ST, Miles PG. 1989 - Edible mushrooms and their cultivation. CRC Press, Inc. Florida.

De Silva M, Naozuka J, Oliviera V, Vancetti D, Bazzolli H. Kasuya C. 2012 - Enrichment of Pleurotus ostreatus mushrooms with selenium in coffee husks. Food Chemistry, 131, 558563.

Dong J, Zhao L, Cai L, Fang H et al. 2014 - Antioxidant activities and phenolics of fermented Bletilla formosana with eight plant pathogen fungi. Journal of Bioscience and Bioengineering, 118, 396-399.

Facchini J, Alves E, Aguilera C, Gern R et al. 2014 - Antitumor activity of Pleurotus ostreatus polysaccharide fractions on Ehrlich tumor and Sarcoma. International Journal of Biological Macromolecules, 68, 72-77.

Falandysz J. 2008 - Selenium in edible mushrooms. Journal of Environmental Science, 26, 256299.

Fasoranti OF, Ogidi CO, Oyetayo VO. 2018 - Phytochemical constituents and antimicrobial evaluation of ethanolic extracts from Pleurotus spp. cultivated on substrate fortified with selenium. Microbial Biosystems 3(2), 29-39.

Fernandes A, Barros L, Martins A, Herbert P, Ferreira R. 2015 - Nutritional characterisation of Pleurotus ostreatus (Jacq. ex Fr.) P. Kumm. Produced using paper scraps as substrate. Food Chemistry, 169, 396-400.

Guo YX, Pan DD, Li H, Sun YY, Zeng XQ. 2013 - Antioxidant and immunomodulatory activity of selenium exopolysaccharide produced by Lactococcus lactis subsp. lactis. Food Chemistry, 138, 84-89.

Hua D, Liua Q, Cuib TH, Wanga H et al. 2000 - Effects of amino acids from selenium-rich silkworm pupas on human hepatoma cells. Life Science, 77, 2098-2110.

Huang S, Lin C, Tsai Y. 2015 - Vitamin D2 content and antioxidant properties of fruit body and mycelia of edible mushrooms by UV-B irradiation. Journal of Food Composition and Analysis, 42, 38-45.

Jayakumar T, Thomas A, Sheu J, Geraldine P. 2011 - In-vitro and In-vivo antioxidant effects of the oyster mushroom Pleurotus ostreatus. Food Research International, 44, 851-861.

Kalac P. 2012 - Chemical composition and nutritional values of European species of wild growing mushrooms. Mushrooms: Types, properties and nutritions. Nova science publishers Inc. Pp129-152.

Kayode RMO, Olakulehin TF, Adedeji BS, Ahmed O et al. 2015 - Evaluation of amino acid and fatty acid profiles of commercially cultivated oyster mushroom (Pleurotus sajor-caju) grown on gmelina wood waste. Nigerian Food Journal, 33, 18-21.

Krishnamoorthy D, Sankaran M. 2014 - Pleurotus ostreatus: an oyster mushroom with nutritional and medicinal properties. Journal of Biochemical Technology, 5(2), 718-726.

Li S, Shah N. 2015 - Effects of Pleurotus eryngii polysaccharides on bacterial growth, texture, properties, proteolytic capacity, and angiotensin-I-converting enzyme - inhibitory activities of fermented milk. Journal of Dairy Science, 98, 2949-2961.

Ling M, Zhang Y, Zhao Y, Yu J, Liu A. 2017 - Chemical characteristics of selenium polysaccharide from Pleurotus ostreatus and antioxidant activities in-vitro. MOJ Drug Design Development and Therapy, 1(4), 00020.

Mao GH, Zou Y, Feng WW, Wang W, Zhao T. 2014 - Extraction, preliminary characterization and antioxidant activity of Se-enriched Maitake polysaccharide. Carbohydrate Polymer, 101, 213-219.

Mishra K, Pal S, Arunkumar R, Chandrashekara C et al. 2013 - Antioxidant properties of different edible mushroom species and increased bioconversion efficiency of Pleurotus eryngii using locally available casing materials. Food Chemistry, 138, 1557-1563.

Mitra P, Khatua S, Acharya K. 2013 - Free radical scavenging and NOS activation properties of water soluble crude polysaccharide from Pleurotus ostreatus. Asian Journal of Pharmaceutical and Clinical Research, 6(3), 67-70. 
Oyetayo VO, Dong CH, Yao YJ. 2009 - Antioxidant and antimicrobial properties of aqueous extract from Dictyophora indusiata. The Open Mycology Journal, 3, 20-26.

Poniedzialek B, Mleczek M, Niedzielski P, Siwulski M et al. 2017 - Bioenriched Pleurotus mushrooms for deficiency control and improved antioxidative protection of human platelets. European Food Research and Technology, 243, 2187-2198

Ren D, Jiao Y, Yang X, Yuan L, Zhao Y. 2015 - Antioxidant and antitumor effects of polysaccharides from the fungus Pleurotus abalonus. Chemico- Biological Interactions, 237, 166-174.

Saha K, Acharya S, Roy A. 2012 - Antioxidant level of wild edible mushroom: Pleurotus djamor (Fr.) Boedijn. Journal of Agricultural science and Technology, 8(4), 1343-1351.

Sharareh R, Sara S, Taher N, Sattari A. 2016 - Antioxidant potential and other medicinal properties of edible mushrooms naturally grown in Iran. Biomedical Research, 27(1), 240-247.

Skinner HCW 2005 - Biominerals. Mineralogical Magazine, 69(5), 621-641.

Synytsya A, Kim WJ, Kim SM, Pohl R et al. 2010 - Structure and antitumor activity of fucoidan isolated from sporophyll of Korean brown seaweed Undaria pinnatifida. Carbohydrate Polymer, 81(1), 41-48.

Tibuhwa DD, Lyantagaye SL, Mshandete AM. 2012 - Effect of different post-harvest treatments on nutritive and antioxidant activities of edible Coprinus cinereus (Schaeff) S.Gray from Tanzania. International Journal of Research Biological Science, 2, 150-156.

Turlo J, Gutkowska B, Herold F. 2010 - Effect of selenium enrichment on antioxidant activities and chemical composition of Lentinula edodes (Berks) Pegl. Mycelial extracts. Food Chemisty Toxicology, 48, 1085-1091.

Vamanu E. 2012 - In-vitro antimicrobial and antioxidant activities of ethanol extract of lyophilized mycelium of Pleurotus ostreatus PQMZ91109. Molecules, 17, 3653-3671.

Vetchinkina E, Loshchinina E, Kursky V, Nikitina V. 2013 - Reduction of organic and inorganic selenium compounds by the edible medicinal basidiomycete Lentinula edodes and the accumulation of elemental selenium nanoparticles in its mycelium. Journal of Microbiology, 51, 829-835.

Wang J, Wang B, Zhang D, Wu Y. 2016 - Selenium uptake, tolerance and reduction in Flammulina velutipes supplied with selenite. PeerJ, 4, 1993.

Wei J, Zeng C, Gong Q, Yang H et al. 2015 - The association between dietary selenium intake and diabetes: a cross-sectional study among middle-aged and older adults, Nutritional Journal, 14: 18.

Wenk H, Bulakh A. 2004 - Minerals: their constitution and origin. Cambridge University Press, Pp 10.

Yang J, Lin H, Mau L. 2002 - Antioxidant properties of several commercial mushrooms. Food Chemistry, 77, 229-235.

Zhang L. Li D, Gao P. 2012 - Expulsion of selenium/protein nanoparticles through vesicle-like structures by Saccharomyces cerevisae under microaerophilic environment. World Journal of Microbiology and Biotechnology, 28(12), 3381-3386. 